\title{
WINDOW BREAKAGE BY BOMB-BLAST
}

$\mathrm{T}$ HE October number of the Journal of the Institute of Physics contains a special article by Dr. H. Moore, director of research for Pilkington Brothers at St. Helens, dealing with some physical problems of war-time window breakage. The effects of bomb-blast were studied experimentally by using small 2-lb. charges of blasting powder exploded under suitable conditions. Instantaneous photography of 7 -ft. square 1 -in. plate glass windows showed that typically, under blast, the damage occurs in two stages. In the first, during the compression period the centre of the glass is forced inwards as a diaphragm, and ring and radial cracks develop. In the second stage, before the pieces have time to separate, the 'suction' half of the wave comes into effect and the pieces fall towards the bomb. If the glass is very near to the bomb so that all the air is displaced by the gases from the explosive, the broken pieces are driven away from the bomb. Short of blocking up a window with brickwork or enclosing it in shutters of heavy timber or stout steel it is practically impossible to safeguard the glass against fracture.

Attention was therefore directed to studying methods of preventing personal injury from flying fragments of glass. Consistent with previous results, sheets of transparent cellulose or fabric are effective if firmly fixed to the glass and carried well over and securely fixed to the edges of the window frame. Complete coverings are always better than separate strips of the same materials. The adhesive must be chosen with care, but ordinary flour paste as used by paperhangers may be used with reasonable safety. Although sodium silicate or water-glass gives excellent adhesion the glass will be etched and left permanently 'greyed'. Toughened glass and panes reinforced internally with wire mesh stood up well to the effects of blast.

Unless the explosion is very near to the window, glass fragments due to blast usually burst outwards. Fragments of glass, debris or bomb casing may, however, still be thrown inwards. Some protection from these is secured by 'lengthening the time of the blow'. For this purpose leaded panes, thick curtains, two or three thicknesses of hessian or $\frac{1}{2}$-in. wire netting stretched on wooden frames and hanging freely some 3-6 in. from the glass have all proved effective.

In the same article the problem of blacking-out roof lights is briefly discussed. One solution was the use of coloured sources of artificial light emitting only a restricted range of the visible spectrum. The windows and roof-lights were then painted with a varnish transmitting only the complementary visible range. When workers found diffieulty in getting accustomed to the coloured lighting, the quick and cheap method of painting the glass with black paint was widely adopted. Reasoning showed that windows exposed to strong sunlight might crack unless they were painted upon the outside--or upon the inside, according to the argument used. Observation showed that the windows were liable to crack in strong sunlight, on whichever side of the glass the paint was put. A study of the conditions showed that cracking was due to temperature differences between different regions of the glass sheet, and not to differences of temperature through the thickness. Cracking was avoided when all parts of the glass, and particularly the edges, were exposed to the radiation in the same way as the centre and if the edges were constrained no more rigidly than in the ordinary fixing with putty.

\section{INDIAN FISHES OF ECONOMIC VALUE}

$\mathrm{S}^{\mathrm{E}}$ VERAL interesting papers on Indian fishes are included in recent numbers of the Records of the Indian Museum. The most important of these are two on the Indian shad " On Some Early Stages in the Development of the so-called Indian Shad", Hilsa ilisha (Hamilton) by K. Krishnan Nair ${ }^{1}$ and "Further Observations on the Bionomics and Fishery of the Indian Shad", Hilsa ilisha (Hamilton), in Bengal waters by Sunder Lal Hora and K. K. Nair $\left.{ }^{1}\right)$. Hilsa is a clupeoid, closely related to the herring, and forms an important fishery. It breeds in the river throughout the year, and the two breeding peaks, large and small, are shown to be correlated with the flooding of the river owing to the monsoon and the nor'westers respectively. The young migrate down the river, and the upstream migration on which the main fishery depends is attributed to the monsoon and the state of maturity of the migrating individuals. A brief account is given of fluctuations in the year-toyear Hilsa fishery, and it is surmised that a five-year cycle exists in the fishery of this species. Hilsa can flourish well in confined fresh waters and even attain maturity. From the discovery of a regular fishery of young Hilsa in cold weather near Calcutta it has been suggested that more attention should be paid to the conservation of the Hilsa fisheries rather than to the establishment of hatcheries for the artificial rearing of the fish.

The collection and hatching of the eggs continues as a routine at Madras and, in Calcutta, owing to the continuation of biological investigations at the Pulta Waterworks by the Zoological Survey of India, a considerable amount of information on the bionomics of this fish has been collected. It was from this latter material that Nair made his observations on the larval forms, giving special attention to the number of vertebræ and changes in the relative proportions of the fish during growth.

T. J. Job ("On the Breeding and Development of Indian 'Mosquito-fish' of the genera Aplocheilus McClelland and Oryzias Jordan and Snyder"2) has investigated the life-histories of those fishes which are commonly used as mosquito controls. The genus Aplocheilus is the most important, and the breeding of three species of these is described; also that of Oryzias melastigma. The so-called 'killifishes' have 